\title{
LA ECONOMÍA DEL FRANQUISMO DESDE EL EXILIO EN MÉXICO (1939-1960)
}

JOSÉ MA. GÓMEZ HERRÁEZ*

\begin{abstract}
RESUMEN
Este trabajo supone una aproximación a diversos enfoques, dentro del exilio español en México, sobre la economía de su país de origen durante 19391960. Se parte tanto de textos de prensa como de reflexiones más detenidas en libros y algunas conferencias y ponencias. En la primera parte se revisan especialmente las críticas al intervencionismo económico y las interpretaciones de dependencia en el periódico comunista España Popular y, con menos énfasis, en el anarcosindicalista Solidaridad Obrera y en el socialista Adelante. J unto a la valoración de los efectos que en la agricultura y en la industria produjeron las medidas reguladoras, se polariza la atención en las relaciones con la Alemania nazi y después con Estados U nidos. En la segunda se consideran trabajos que evocan las experiencias de la Segunda República, se presentan programas de actuación o contemplan asimismo, desde perspectivas diversas, los problemas en las relaciones económicas externas y en las políticas económicas de aquellas décadas.
\end{abstract}

* Doctorado en Historia Contemporánea en la Universidad de Valencia, España, en 1991. Profesor en la U niversidad de Castellón, España, en el área de Historia e Instituciones E conómicas del Departamento de E conomía. Entre sus trabajos, destacan Instituciones, perspectivas económi cas y problemas sociales durante el franquismo. Al bacete, entreel silencio y é éxodo rural, 1939-1962, Instituto de Estudios Albacetenses, 1993, y E conomía y posguerra desde el exilio. EI otro debate, Castellón, Universidad J aume I, 2000. 


\section{The Spanish Economy During the Franco Years as Seen BY EXILES IN MEXICO (1939-1960)}

This article summarizes some of the approaches used by Spanish exiles in Mexico to analyze the economy of their country of origin during the period from 1939 to 1960. It is based on newspaper articles and more detailed reflections in books, as well as a number of lectures and talks. The first part focuses mainly on the criticisms of economic interventionism and the interpretations of dependence in the communist newspaper España Popular, and, somewhat less so, on the anarcho-syndicalist Solidaridad Obrera and the Socialist Adelante In addition to providing an assessment of the effects of regulatory measures on agriculture and industry, the article focuses on relations with Nazi Germany and subsequently with the United States. The second part analyzes papers that evoke experiences of the Second Republic, describes programs of action and uses a variety of perspectives to analyze problems in the external economic relations and economic policies of the time.

\section{L'ÉCONOMIE DU FRANQUISME VUE DE L'EXIL AU MEXIQUE}

\section{(1939-1960)}

L'article propose un survol de différentes approches de l'économie espagnole au cours de la période 1939-1960, par des Espagnols exilés au Mexique. L'étude est menée à partir d'articles de presse ainsi que de réflexions plus approfondies tirées de livres et de quel ques conférences et exposés. Dans la première partie de l'étude sont passées en revue tout particulièrement les critiques de I'interventionnisme économique et les interprétations de dépendance parues dans le journal communiste España Popular et, avec moins d'insistance, dans le journal anarcho-syndicaliste Solidaridad Obrera et le journal socialiste Adelante. À côté de l'évaluation des conséquences des mesures de régulation dans l'agriculture et dans l'industrie, l'attention se concentre sur les relations avec l'Allemagne nazie, puis avec les États-U nis. La deuxième partie comprend un examen de textes évoquant les expériences de la Deuxième République, une présentation des programmes d'action ou une évocation, dans des perspectives diverses, des problèmes dans les relations économiques extérieures et dans les politiques économiques au cours de ces décennies.

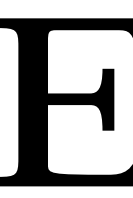

n la profunda meditación que los intelectuales exiliados tras la guerra civil desarrollaron sobre E spaña, la política económica y sus conexiones internacionales resultan importantes por varias razones. Si bien inevitables dificultades lastraron su desarrollo, el interés de estas reflexiones 
resalta por la formación y experiencia acumuladas por varios de estos pensadores como especialistas, como políticos o simplemente como observadores atentos a lo que en España sucedía. Podría entenderse que la tan señalada lejanía y el rechazo al régimen franquista podían interferir en la corrección y serenidad de las interpretaciones y velar las percepciones de la realidad. Pero, aparte de la imposibilidad permanente de deslindar entre valoraciones objetivas y subjetivas por la presencia condicionante, necesaria, de una concepción ideológica de las relaciones sociales y políticas, estos argumentos, aunque reales, pueden transformarse para subrayar precisamente el interés de estas visiones: la distancia y el carácter de oposición constituyen también un aval del sentido crítico y de la amplitud de perspectivas, respaldados en casos como el de M éxico por las oportunidades de contraste y debate en un marco institucional y cultural más abierto. Así, en los enfoques sobre las relaciones económicas externas podían pesar el afán de aislar al régimen y las simpatías y antipatías internacionales, variables según los criterios ideológicos, pero que a la vez, carecían del triunfalismo, los rechazos o la cautela exigidos, según los casos, bajo el régimen franquista.

Las dificultades de información, ya presentes dentro de España, const ituían un obstáculo en los estudios sobre su realidad económica. Y, como señalaba Elías Díaz a propósito de otras esferas del pensamiento, la situación política marcaba una barrera, aunque no total, en el diálogo con pensadores del interior, incluso de matiz liberal. ${ }^{1}$ En cierta medida, estos problemas quedaban mitigados por la llegada de revistas especializadas, como El Economis ta, de Madrid, fuentes estadísticas más o menos fiables y obras de autores que, como Higinio Paris o Manuel de Torres, figuraban entre los más difundidos en España. ${ }^{2}$ EI propio contacto con otras realidades nacional es podía enriquecer las posibilidades de contraste, como ejemplifica el pequeño ensayo del republicano Vázquez Humasqué en el periódico Las Españas, en 1946, titulado "El problema agrario en España y México".

En este trabajo se comentarán algunos argumentos más repetidos o elaborados sobre la economía española y sus vínculos externos con la producción de exiliados ubicados, sobre todo, en México. Pese a la escasez de economistas especializados, ${ }^{3}$ la notable convergencia de intelectuales y políticos de

1 Elías Díaz, Pensamiento español en la era deFranco (1939-1975), Madrid, Tecnos, 1983, p. 70.

2 J uan Velarde Fuertes, "La base ideológica de la realidad económica española”, en J osé Luis García Delgado (dir.), España. Economía, Madrid, Espasa-Calpe, 1988, pp. 986 y ss.

$3 \mathrm{Si}$ el alto interés historiográfico en el pensamiento del exilio español no se ha extendido a los planteamientos económicos es, en parte, por el bajo número de especialistas entre los intelec- 
diversas tendencias que afrontaron tales temas convierten este ámbito en especial mente representativo. Muchos de los aspectos en que incidían estos autores han continuado alimentando la reflexión historiográfica en España hasta la actualidad, por lo que interesa establecer, al menos, al gunas comparaciones general es. Los textos consultados pueden agruparse en dos categorías: los procedentes de prensa y los análisis más detenidos de libros, conferencias y ponencias. Los primeros permiten observar visiones de varios problemas desde diversos planos ideológicos, si bien con distinta intensidad según el espacio ocupado por cada periódico. Las lagunas ideológicas y temáticas en el capítulo periodístico quedan en parte compensadas por la mayor diversidad que presentan los estudios hallados.

\section{Aproximaciones en España Popular}

De todos los periódicos editados por los exiliados españoles en M éxico, Espa ña Popular, de tendencia comunista, es el que presenta mayor continuidad, frecuencia y proyección temática. Sin duda, a ello contribuyeron sus mejores facilidades de financiación y su contacto con grupos de España y de otros países, principalmente de la URSS, de donde llegan varios artículos. También reproduce varios trabajos de Mundo Obrero, el órgano de la oposición comunista española en Francia. En España Popular, la acción represiva franquista, la evolución económica del país o la política internacional adquieren más desarrollo que en otros periódicos, más netamente concentrados en campos también presentes en aquél, como cuestiones doctrinales, tácticas de oposición o evocación de hitos y experiencias - distintos, según cada tendencia- durante la República y la guerra. El periódico se enmarca hasta muy tarde en la dependencia ideológica del estalinismo que M. Tuñón de Lara atribuía genéricamente al Partido Comunista de España (PCE $),{ }^{4}$ pero en las reflexiones económicas, aun con el peso de concepciones definidas, no parece

\footnotetext{
tuales que alimentaron ese éxodo en unos momentos en que tales estudios estaban alcanzando rango académi co vinculado sobre todo con el estudio del derecho. En las nóminas de pensadores, artistas e intelectual es del exilio, los nombres de economistas aparecen, también, como una especie de apéndice del grupo de juristas, con la vinculación a la UNAM y la actuación asesora en diversos órganos como manifestaciones principales de su trascendencia pública. Es el caso, por ejemplo, del análisis de Salvador Reyes, "J uristas, economistas, sociólogos", en AA. VV., El exilio español en México, 1939-1982, México, Salvat, Fondo de Cultura Económica, 1983, primera edición en 1962. Entre los nombres citados en este tipo de aportaciones, aparecen Manuel Sánchez Sarto, J avier Márquez, Antonio Sacristán, Ramón Ramírez, Alfredo Lagunilla, J uan Antonio Freijo, García Méndez y Álvaro de Albornoz de la Escosura.

4 Manuel Tuñón de Lara, España bajo la dictadura franquista (1939-1975), Historia deEs paña, tomo x, Barcelona, Labor, 1982, p. 238.
} 
que se fijaran márgenes tan rígidos como en política internacional y en otros temas.

Las aproximaciones a la situación del sector agrario, tanto a través de textos monográficos como en apreciaciones general es sobre la economía, conforman una de las líneas temáticas más recurrentes en el periódico. ${ }^{5} \mathrm{Al}$ primar la denuncia de lo visible e inmediato, no se hallan en estos trabajos sutilezas analíticas sobre el sector dentro del conjunto de la economía, pero varias de las afirmaciones no han dejado de ser corroboradas en igual o en cierto grado por la historiografía. ${ }^{6}$

Entre las denuncias más repetidas, aunque no muy desarrolladas, aparece la sustitución del objetivo de distribución de la tierra, tras 1936-1939, por una "demagógica" práctica colonizadora, con escasos asentamientos de camp e s inos. Contra toda dirección de reparto, sorprendía cómo los grandes propietarios, inmediatamente a la guerra e incluso antes de cursar la legislación al respecto, habían recuperado las tierras afectadas por las reformas y ocupaciones de los años treinta.

Los cupos exigidos de trigo y de otros productos podían considerarse, por los bajos precios ofrecidos, verdaderas "acciones de requisa". Durante la conflagración mundial, el periódico apuntaba, en consonancia con una valoración muy difundida en el exilio y que en la historiografía más reciente sólo aparece como una funcionalidad adicional, la exportación de estos productos a las potencias del Eje. Algunos autores han destacado la importancia de estas partidas, como los minerales, relacionándolas en parte con la liquidación de deuda de guerra. ${ }^{7}$ Aparte de los cupos oficiales, el periódico comunista denuncia cons-

5 Como ejemplos significativos, "Racionamiento, estraperlo y hambre", núm. 79, 22 de noviembre de 1941; "Perspectiva de mayores hambres en España", núm. 248, 6 de julio de 1946; "La Asamblea de hermandades de labradores y ganaderos", núm. 321, 22 de noviembre de 1946; "EI Congreso Sindical de la Tierra organizado por Falange", núm. 400, 28 de mayo de 1948; y "Terminemos con la intervención de las cosechas", núm. 675, 4 de septiembre de 1953. Algunos textos se refieren a la situación de determinadas zonas, como Galicia, 7 de diciembre de 1940; Albacete, 22 de septiembre de 1944; Valladolid, 4 de marzo de 1945 o Cantabria, 30 de diciembre de 1945.

6 Como síntesis y reflexión gl obal, sirve para observar contrastes y similitudes con las visiones en el exilio la aportación clásica de Carlos Barciela, "Los costes del franquismo en el sector agrario: la ruptura del proceso de transformaciones", introducción a la segunda parte de R. Garrabou, C. Barciela y J .I . J iménez Blanco (eds.), Historia agraria dela España contemporá nea. 3. El fin dela agricultura tradicional (1900-1960), Barcel ona, Crítica, 1986. Más recientes son las reflexiones reunidas en Papeles de Economía Española, número 73, 1997; C. Barciela, "La modernización de la agricultura y la política agraria"; A. M. Bernal, "La modernización de la agricultura española"; Ramón Garrabou, "Políticas agrarias y desarrollo de la agricultura española contemporánea: unos apuntes", y J osé María Sumpsi, "La modernización de la agricultura y el desarrollo económico".

7 Ángel Viñas, Guerra, dinero, dictadura. Ayuda fascista y autarquía en la España de Fran co, Barcelona, Crítica, 1984, pp. 255-256; J ordi Catalán, La economía española y la Segunda 
tantemente la superposición de otros "cupos extraoficiales" por cargos y fuerzas públicas en los pueblos.

De acuerdo con una afirmación repetida, los bajos precios ofrecidos habían incitado al estraperlo y a la dedicación a cultivos alternativos. Pero, además, en lo que puede constituir una de las aportaciones más Ilamativas, aunque no ignoradas en la historiografía actual, ${ }^{8}$ numerosos textos del periódico al uden a un verdadero y peculiar "absentismo" entre pequeños cultivadores: la falta de estímulo estaba conduciendo - se decía - al retroceso hacia meros objetivos de autoconsumo, productos de baja rentabilidad o incluso utilización para ganado de la cosecha de al imentos de consumo humano. Tampoco los consumidores se beneficiarían de la actuación intervencionista, puesto que varios sectores carecían de poder adquisitivo suficiente para acudir a lo ofrecido en estraperlo.

Por la escasa capitalización de la agricultura familiar y por las posibilidades fáciles de beneficios de los terratenientes - especiales beneficiarios del mercado negro-, se explicaba la escasa adopción de innovaciones. Las ayudas institucionales al campesinado apenas rebasarían la esfera de las promesas y de la propaganda. Además, los pequeños cultivadores y los jornaleros carecerían de una representatividad efectiva dentro del tejido sindical, y en concreto, en su expresión local, las hermandades de labradores y ganaderos. Estas últimas denuncias, que también la historiografía reciente ha corroborado - aunque matizando la rotundidad de esa exclusión y vislumbrando variedades regionales-, se agudizaban ante eventos oficiales que el periódico tildaba de pseudointegradores. Así ocurrió, por ejemplo, ante la primera Asamblea Nacional de Hermandades Sindicales, celebrada en Madrid en octubre de 1946, o ante el Congreso Sindical de la Tierra organizado por F alange en Sevilla, en la primavera de 1948.

Aunque menos numerosas, no faltan también en España Popular, desde temprano, las críticas al intervencionismo industrial, que adquieren clara prioridad en los comentarios sobre este sector después de la conflagración mundial. Un cuadro general se perfila mediante esta serie de trabajos: ${ }^{9}$ la

Guerra Mundial, Barcel ona, Ariel, 1995, p. 212, y del mismo autor, “Sector exterior y crecimiento industrial. E spaña y Europa, 1939-1959", en Historia Industrial, 1995, núm. 8, p. 110.

$8 \mathrm{Ha}$ sido señalado, por ejemplo, por C. Barciela, op. cit., 1986, p. 393, y por Roque Moreno, La autarquía en Alicante (1939-1952), Alacant, Institut de Cultura J uan Gil-Albert, 1995, p. 159.

9 Entre otros varios, pueden destacarse "Informe del interior. La situación económica de Cataluña" (núm. 267, 16 de noviembre de 1945); “Los capitalistas españoles se pronuncian contra el sistema franquista y por la libertad de la industria y del comercio" (núm. 337, 14 de marzo de 1947); "La grave crisis de la industria en la España franquista” (núm. 378, 26 de diciembre de 1947); 
regulación de los precios frenaba el estímulo a la producción; el fuerte reglamentismo alumbraba una burocracia abrumadora; en la gestión de los controles apenas participaban los pequeños empresarios y artesanos; las cargas fiscales eran excesivas, sobre todo para estos dos últimos grupos; resultaban escasos los insumos fundamentales, tanto de materias primas como de maquinaria y recursos energéticos; y finalmente el control de la mano de obra y los bajos niveles salariales, si bien disminuían los costos unitarios, hacían descender el rendimiento laboral y el poder adquisitivo de la población.

Las dificultades del sector industrial quedaban directamente relacionadas con las del comercio exterior, descubriéndose problemas acumulativos de dirección circular: el relativo aislamiento y la intervención, mediante el control del mercado de divisas y el ofrecimiento de licencias, entorpecían el volumen de intercambios y dificultaban la disponibilidad de medios de pago; ello repercutía a su vez negativamente en los niveles de producción, por la insuficiencia de insumos externos, lo que disminuía y encarecía el potencial de producción susceptible de exportación. Es cierto, a la vez, que al gunos trabajos del periódico comunista, como se hacía desde otros de filiación anarquista, consideraban contraproducente el impulso de las exportaciones mientras en el interior dominase la escasez.

Esta prensa también insiste en los resultados distintos que el intervencionismo desencadenaba entre las empresas: mientras aquellas con más contactos políticos se beneficiaban de las oportunidades de ampliación y mejora, de los cupos de insumos y de las posibilidades del mercado - incluyendo la práctica estraperlista-, otros muchos empresarios, principalmente los de menor potencial de capital, quedaban prácticamente al margen. De este modo, el periódico insistía en una forma de desigualdad de oportunidades que las investigaciones sobre el periodo no han dejado de repetir a lo largo del tiempo. ${ }^{10}$

Los efectos del intervencionismo quedan ligados en el periódico comunista a otro el emento concomitante, el de una fuerte dependencia externa. De acuerdo

“La crisis de la industria en Guipúzcoa" (núm. 392, 2 de abril de 1948); y “La crisis de la industria y del comercio" (núm. 403, 18 de junio de 1948). Los ejemplos podrían multiplicarse si se suma la cantidad de trabajos referidos a sectores concretos como el eléctrico, el textil catalán o el siderúrgico.

10 Entre otros muchos, pueden considerarse Ramón Tamames, Estructura económica de España, Madrid, Guadiana, 1969, cuarta edición, p. 453; Carlos Moya, El poder económico en Es paña (1939-1970), Madrid, Tucar, 1975, pp. 143 y ss.; J uergen B. Donges, La industrialización en España. Políticas, logros, perspectivas, Barcelona, Oikos-tau, 1976, pp. 45 y ss.; Carme Molinero y Pere Ysás, “Los industriales catalanes durante el franquismo", en Revista de Histo ria E conómi ca, año 1990, núm. 1, pp. 111-112; J osé Antonio Miranda y J uan Francisco Pérez Ortiz (1992), “Poder político y favor económico. EI Archivo de Nuevas Industrias como fuente 
con numerosos artículos, junto a los grupos dominantes - terratenientes, alta burguesía financiera, burocracia falangista-, las dos potencias fascistas en un primer momento, y Estados Unidos después, marcarían la dirección de las relaciones económicas y del desarrollo del país. Aspectos generales o puntuales, unas veces representativos de procesos amplios y otras veces más aislados, se muestran como pruebas de esa subordinación.

A principios de los años cuarenta, la dependencia de los países del Eje, principalmente de Alemania, es contemplada como invasión imperial. Quizá, la mejor expresión de esta concepción, común a otras tendencias de izquierda, aparece en la designación despectiva del régimen como nazi-falangismo. Lo que $A$. Viñas analiza como actuaciones ambivalentes del régimen franquista ante presiones depredatorias, y J . Catalán como vinculación prioritaria voIuntaria, era contemplado por estos autores de inspiración marxista como verdadera simbiosis o vertebración entre intereses exteriores e interiores, que conseguía imperar en los resortes del Estado e hipotecaba la voluntad nacional. ${ }^{11}$ La el evada generalización, la desvirtuación probable de al gunas noticias, la transformación algo artificiosa de sospechas e indicios en sólidas constataciones y la importancia exagerada de algunos factores explicativos podían originar visiones parcial o ampliamente distorsionadas de la realidad. Tales elementos enturbian la convicción al tratar de dirimir las conexiones internas y externas entre lo político, lo económico y lo social.

para el análisis de las presiones políticas en una economía intervenida", en I Encuentro de Investigadores del Franquismo, Barcelona, noviembre de 1992, pp. 9-11; J ordi Catalán, "Reconstrucción, política económica y desarrollo industrial del sur de Europa, 1944-1953", en Leandro Prados de la Escosura y Vera Zamagni (eds.), EI desarrollo económico en la E uropa del Sur: Espa ña el talia en perspectiva histórica, Madrid, Alianza Universidad, 1992; Roque Moreno, en op. cit., 1995, pp. 265-271, y Francisco J avier Fernández Roca, “Estrategias empresariales en una economía intervenida", en III Encuentro de Investigadores del Franquismo, Sevilla, enero de 1998, pp. 182-183.

11 En sucesivos capítulos, A. Viñas (1984) relativizaba la aproximación del régimen franquista al Tercer Reich por el interés en escapar a su afán de explotación (p. 165) y por la tradicional atracción económica de Inglaterra y Francia (p. 247). Aunque valoraba el influjo fascista en la autarquía, también sugería que "más subterráneamente, es posi ble que constituyera un mecanismo compensador de la flexión ante lo que se consideraban atropellos económicos nazis..." (p. 209). También descubrían contradicciones J . Clavera, J .M. Esteban, M.A. Monés, A. Montserrat y J . Ros Hombravella, en Capitalismo español: de la autarquía a la estabilización (1939-1959), Madrid, Cuadernos para el Diálogo, 1973, vol. I. Aparte de la imposibilidad de una autosuficiencia pura y de las dependencias respecto a los países aliados en el aprovisionamiento, estos autores destacaban la impronta en las relaciones económicas de las tensiones y distensiones políticas internacionales del régimen. Además, aclaran: “Al igual que en Alemania e Italia, la autarquía española no fue tanto una exigencia ideológica del nuevo régimen cuanto una forma de asimilar la amarga experiencia de depender del exterior" (p. 90). 
Algunas muestras de estos argumentos permiten observar, en verdad, grados distintos de desfiguración y de sintonía con los criterios y ponderaciones de investigadores posteriores. En la política inicial de colonización agraria, gran parte del escaso reparto de tierras se haría entre col onos italianos (número 34, 19 de octubre de 1940). Los problemas de abastecimiento al imentario derivarían de la exportación de productos agrarios a Italia y Alemania (por ejemplo, el núm. 79 del 22 de noviembre de 1941, "Racionamiento, estraperlo y hambre"). El férreo intervencionismo agrario se explica bajo los objetivos de aprovisionamiento al ejército hitleriano (por ejemplo, el núm. 96 del 5 de agosto de 1942). En las grandes empresas industriales, varios accionistas y consejeros, tanto extranjeros como españoles, habrían sido desplazados por alemanes favorables a Hitler o incluso enviados por él. De acuerdo con un artículo, tanto las industrias siderúrgicas, metalúrgicas, mineras y de astiIleros, como incluso el textil catalán, habían pasado a producir material de guerra y de equipo, y también productos de consumo, para el ejército nazi, bajo asesoramiento de técnicos al emanes (núm. 180, del 10 de marzo de 1944, "La dominación nazi en la industria española"). Menos en el primer caso, estas afirmaciones se conectan con las realizadas por al gunos investigadores, si bien sin atribuirles un alcance tan alto, como se decía más arriba al hablar del intervencionismo agrario.

Durante 1945 y 1946 aparecían numerosos artículos —uno de ellos, con el sugestivo título "España, colonia nazi" - que trataban de mostrar cómo la dependencia hacia la economía alemana no había dejado de crecer durante la contienda, prolongándose y camuflándose, tras la derrota, con cambios de titularidad en las empresas y el desarrollo del comercio de contrabando. Sin duda, ante el fin de los fascismos, al contemplar inminente un posible apoyo internacional contra el régimen franquista, aumentó la insistencia en denunciar estas connivencias. Al interpretar los problemas y las directrices económicas, tales argumentos no desplazan totalmente otros de tipo técnico, pero éstos siempre se entienden en un contexto que incorpora relaciones sociales, intereses políticos y conexiones exteriores. Así, en un artículo del 27 de septiembre de 1946, titulado "Venden e hipotecan todo para lograr divisas", se unían acusaciones contra el franquismo por su intenso programa de militarización y sus facilidades para la huida de nazis con un rechazo categórico hacia el interés en estimular las exportaciones para obtener divisas. A la vez que se explicaba ese afán de medios de pago dentro del programa general de rearme, se juzgaba contraproducente estimular la exportación de productos de primera necesidad, cuando en el interior se extendían la escasez y la inflación. 
Desde la segunda mitad de los años cuarenta, España Popular sustituye las denuncias contra la subordinación a Alemania por las dirigidas sobre un proceso similar hacia Estados Unidos. Sucesivos artícul os tratan de mostrar las nuevas conexiones entre cargos políticos, ol igarquía financiera y grandes compañías estadounidenses. Los títulos ya evocan el cambio: "I mpidamos que E spaña sea convertida en colonia norteamericana”, o “La industria eléctrica española, orientada hacia la producción de guerra, está en manos de monopolios yanquis". Abundan las citas de empresas industriales españolas, incluyendo las del Instituto Nacional de Industria (INI), que, con su vinculación ya anterior a la gran banca y a políticos destacados, pasan ahora a vincularse a multinacionales estadounidenses. La visión sobre los lazos internos de las empresas industriales con la banca y las instituciones ha sido reafirmada después al observar un proceso que se prolonga en el tiempo, ${ }^{12}$ pero no ha ocurrido así con los vínculos con el capital extranjero, que tienden a ser estimados significativos sól o desde las medidas de apertura de 1959. Esta nueva subordinación económica es considerada paralela e integrada con la de tipo militar que los pactos con Estados Unidos sellan en septiembre de 1953.13

Tres artículos próximos cronológicamente a la firma de los pactos permiten observar con detalle esa vislumbrada relación. En “La grave repercusión en Cataluña de la dependencia económica de España de los intereses monopol istas estadounidenses", del 12 de septiembre de 1952, J osé Moix trataba de explicar la fuerte crisis del sector textil. Como causas, valoraba la falta de algodón y lana, las restricciones eléctricas, la imposibilidad de renovar la maquinaria, la ausencia de créditos y divisas y la baja capacidad adquisitiva interior. Pero como eje del artículo, diferenciaba entre las pequeñas empresas, que sufrirían tales problemas, y aquellas otras mayores, con importantes conexiones políticas y progresivamente ligadas de forma directa o indirecta al capital estadounidense, que incluso se orientarían ya a la exportación. Estas segundas, además de recibir inversiones hasta convertirse en verdaderas filiales de "monopolios yanquis", se beneficiarían también de créditos dirigidos a la importación de la fibra de Estados Unidos.

12 Baste recordar aquí, a modo de ejemplo, a Ramón Tamames, Los monopolios en España, Madrid, ZYX, 1967.

13 Sin destacar un grado de intromisión económica similar, para A. Viñas estos acuerdos manifiestan la clara disposición del régimen, pese a sus alardes nacionalistas, a aceptar importantes recortes de soberanía en unos términos de capitulación que evocaban los de la época imperialista (op. cit., 1984, p. 297), y Los pactos secretos de Franco con Estados Unidos. Bases, ayuda económica, recortes de soberanía, Barcel ona, editorial Grijalbo, 1981. 
Un segundo artículo, "La verdadera situación del comercio exterior", explica la subordinación a la economía estadounidense desde la esfera del intercambio, por la conversión de España en mercado cautivo para varios de sus productos. El resultado sería una balanza de pagos deficitaria. El "hambre de divisas", además de avivar corrupción y favoritismos en la concesión de licencias de importación, contribuiría también al desequilibrio por la necesidad de recurrir al crédito exterior (núm. 677, 18 de septiembre de 1953).

EI tercer artículo, "Consecuencias económicas del pacto yanqui-franquista", aparecido el 30 de octubre de 1953, gira expresamente sobre los resultados inmediatos de los acuerdos de septiembre de 1953. En la explicación genérica del interés estadounidense en los mismos, el articulista combinaba las razones de estrategia militar con los argumentos económicos con que desde perspectivas marxistas se había explicado el imperialismo tradicional:

No interesa a Estados Unidos el desarrollo de la economía, de la industria ni del comercio españoles. Les interesa únicamente convertir España en base de agresión, en colonia productora de artículos agrícolas y hacer de su mercado botín de los monopolistas estadounidenses.

Como balance, el autor contraponía las ventajas para Estados U nidos con los inconvenientes para la economía española, que no sólo no se beneficiaría de una ayuda ante todo armamentista, sino que sufriría en su precario mercado interior la competencia de la producción en serie estadounidense, por el temido desmontaje arancelario unilateral hacia este país. EI aumento de gastos militares por el Estado español, además, acentuaría las cargas fiscales y la inflación, y con ello, la depreciación exterior de la moneda, la carestía y la re ducción de la demanda.

Durante 1954, abundan las denuncias similares sobre los pactos dentro de una vasta campaña de rechazo desde todas las perspectivas (con la política y la militar, la económica y la social). Ya en enero aparecía distribuido en dos números un artículo cuyo título resulta enteramente aclaratorio: "EI pacto yanqui-franquista incrementa la crisis económica". Después, los trabajos de este tipo se multiplicarían. El estrechamiento de lazos con Estados Unidos se juzgaba negativo por el aumento inabordable de la competencia y por el control de canales de distribución. Pero los juicios que llegaban más lejos giraban sobre las consecuencias directas de la ayuda. Se insiste en sus efectos inflacionistas, en su escaso impulso al sistema productivo, en el desarrollo de obras públicas al servicio de los compromisos militares y en detrimento de necesidades nacionales, y en el beneficio indirecto para los bancos españoles, 
que estaban creando sus propias constructoras para participar en los subcontratos previstos en la realización de las bases. Tan al extremo de esta línea que llegaba a rebasarla, un trabajo afirmaba que la producción agraria española se subordinaría al interés alimentario de las tropas estadounidenses aquí asentadas. Aunque no siempre ni con igual alcance, al gunas de estas valoraciones coinciden con las críticas planteadas más recientemente por $\mathrm{A}$. Viñas, como la de la rebaja sensible del al cance de la ayuda económica, subrayando su vinculación al interés militar y sopesando los condicionamientos que suponía la exigencia de un contraval or en pesetas dirigido a fines predeterminados. ${ }^{14}$

Habría que esperar a 1959 para encontrar un nuevo hito que catalizara las críticas de España Popular. Ese nuevo factor institucional fue el Plan de Estabilización y Liberalización, que aunque suponía una ruptura frontal del denostado intervencionismo del periodo autárquico, fue interpretado desde varios textos comunistas dentro de la línea de progresiva dependencia hacia el centro capitalista. Como ejemplo de estas visiones pueden servir dos trabajos incorporados en el número extraordinario con que en mayo de 1960 quiso cel ebrarse el 40 aniversario del origen del PCE. Uno de ellos, titulado "¿Cómo salir de la dictadura?", se debía al nuevo secretario general, Santiago Carrillo, y había sido reproducido antes en el periódico cubano Hoy. Aunque su objetivo básico era el muy común en el exilio de reflexionar sobre las vías para acabar con el régimen, se comenzaban valorando con cierta exhaustividad los efectos inmediatos del Plan. El otro trabajo, de Luis García Largo, entraba directamente en estos resultados bajo el título “La crisis económica de España, ¿un callejón sin salida?". El primero explicaba el Plan como exigencia planteada por la OECE y el FMI para poder recibir préstamos que permitieran afrontar al gobierno franquista los problemas de déficit. El segundo incidía principalmente en el interés del capital exterior y de la propia oligarquía financiera en una actuación de apertura y estabilización que favorecieran el aprovechamiento máximo en la explotación de recursos del país. Ambos textos coincidían en valorar los efectos adversos que la mayor competencia exterior y la disminución del poder adquisitivo en el interior habían significado ya para gran parte de la industria autóctona, cifrando en ello una espiral de cierres de empresas y aumento del desempleo. En aquellos momentos, no se

14 Viñas, op. cit., 1981, pp. 251-275. En un sentido distinto, Clavera y otros., en op. cit., 1973, vol. II, sí atribuían a la ayuda estadounidense cierto papel compensador en la balanza de pagos, a la vez que en la desmovilización de una porción de la contrapartida en pesetas descubrían una funcionalidad antiinflacionista. Para A. Viñas no cabe este dilema último al proyectarse tal cantidad en pesetas, precisamente, en función de la inyección de la ayuda. 
podía prever el cambio de dirección que en un nuevo contexto económico internacional se produciría en los años siguientes. Santiago Carrillo llegaba a manifestar, al aludir a las muestras de descontento entre los distintos sectores económicos y sociales, que también la gran banca y algunos trust industriales habían mostrado sus quejas con la dirección seguida. Si en algunos ámbitos estos grupos financieros e industrial es consideraban insuficiente la liberalización, como en el mercado de trabajo, en otros manifestaban un rechazo pronunciado, como al clamar por la protección exterior del carbón, la siderurgia y los abonos químicos. ${ }^{15}$

\section{VISIONES EN OTROS PERIÓDICOS: ADELANTE Y SOLIDARIDAD OBRERA}

Tanto Adel ante, periódico social ista vinculado a I ndalecio Prieto, como Soli daridad Obrera, anarcosindicalista, adquieren menor desarrollo que España Popular, y ofrecen clara prioridad a los temas programáticos y al análisis político frente a las cuestiones económicas y la información sobre España. En otros, como El Socialista, próximo a J uan Negrín, la presencia de temas económicos es escasa, limitándose a aparecer de modo indirecto por las noticias sobre conferencias o discursos.

En Adelante, aparte de algunas críticas muy genéricas sobre el intervencionismo, aparecen textos que denuncian los efectos económicos y la hipoteca en que el régimen franquista había dejado al país mediante los pactos con Estados Unidos. Así, un artículo de fines de 1955 culpaba a Eisenhower y a Franco de haber convertido a España en traspatio de Estados U nidos, y resaltaba los efectos inflacionistas del gasto militar (noviembre de 1955, "Venta, inflación y hambre"). En otro artículo más tardío, los acuerdos eran contemplados irónicamente como el culmen de una "revolución pendiente" que exponía al país al riesgo de participar en una guerra atómica (mayo-junio de 1958, “EI fuero del trabajo del régimen franquista"). Tradicionalmente, Indalecio Prieto había mostrado gran afán en atraerse el favor estadounidense en la lucha contra el régimen. Por ello, el nuevo rumbo de las relaciones le debió causar una decepción -y como a él, a sus seguidores - sólo equi parable a la que condujo a la ruptura de negociaciones con los monárquicos, tras el estrechamiento de sus contactos con Franco. ${ }^{16}$

15 Un análisis exhaustivo sobre los efectos inmediatos del Plan, incluyendo los específicos sobre los tres subsectores citados, se encuentra en Manuel J esús González, La economía política del franquismo (1940-1970). Dirigismo, mercado y planificación, Madrid, Tecnos, 1979, pp. 240 y ss.

16 Véase J .C. Gibaja Velázquez, Indal ecio Prieto y el socialismo español, Madrid, Editorial Pablo Iglesias, 1995. 
En la prensa socialista y republicana, como en los estudios y conferencias de similares filiaciones, se evocaban frecuentemente las iniciativas agrarias del bienio social-azañista. Las referencias se centraban principalmente en la reforma agraria iniciada en septiembre de 1932, sumando a veces consideraciones sobre la extensión del regadío, como al destacar la anticipación al nuevo régimen en iniciativas como el Plan Badajoz. Menos numerosas son las valoraciones sobre la política reguladora de aquellos mismos años, pese a que el rechazo por la del régimen franquista podría haber servido de contraste y evocación. Un texto de J osé Venegas en Adelante constituye, sin embargo, una de las aproximaciones más detenidas que hemos hallado sobre este tema entre los textos del exilio. Lejos de cel ebrar la fijación de precios de garantía como factor de estímulo en el sector triguero, este autor estimaba que la ampliación de importaciones de este cereal habría resultado más conveniente para la economía nacional, para los trabajadores, para los consumidores y también para los pequeños cultivadores que no cubrían su subsistencia con su producción. A su juicio, era preferible importar cereal y dedicar la superficie a cultivos de exportación más rentables, como vino, aceite, naranjas y productos de conserva. Como J . Pal afox recientemente, ${ }^{17} \mathrm{~J}$. Venegas señal aba los rendimientos decrecientes que el apoyo a los precios provocaba en la superficie triguera. No obstante, no introducía un argumento que Manuel de Torres manejaría más tarde al referirse a este periodo: ${ }^{18}$ el trigo también ofrecía menor costo de oportunidad por los problemas que los subsectores de exportación experimentaban bajo la crisis internacional. J . Venegas confiaba en la sustitución rentable de cultivos mientras rigiera un tratado bilateral con un país cerealícola como Argentina, del que se podría importar trigo y al que se podrían exportar otros productos. Pero, como se sabe, también estos tratados pueden desembocar en problemas importantes en la asignación de recursos, además de suponer, como han manifestado al gunas experiencias históricas, verdaderas situaciones de coacción de un país sobre otro.

En Solidaridad Obrera, el interés en las relaciones económicas externas es bajo si se compara con el examen -aunque al go intemporal - de las estructuras agrarias y del programa colectivizador. Pero también en él domina la imagen del franquismo como motor para la conversión de España, según expresión que aparece entre sus páginas, en "Colonia de Occidente". Como ejemplos, dos artícul os de 1946 relacionaban el fracaso de la revolución libertaria durante

17 J ordi Palafox, Atraso económico y democracia. La Segunda República y la economía española, 1892-1936, Barcelona, Crítica, 1991, pp. 240-249.

18 Manuel de Torres, J uicio dela actual política económica española, Madrid, Aguilar, 1956, pp. 11-12. 
la guerra civil con el recurso a la fuerza militar o al boicot económico por los países fascistas y por los democráticos. Después, subrayaban la permanencia bajo el franquismo de un model o típicamente colonial, difundido ya en el siglo XIx, en que España abastecía a otros países occidentales de minerales y recibía de ellos máquinas, herramientas, carbón y otros productos, sin capacidad para influir en unos ni en otros precios ("Sobre el porvenir de España", 20 de enero de 1946, y "La revolución española. Nuevas perspectivas sociales", 19 de julio de 1946).

En julio de 1959, a la vez que entraba en vigor el plan de estabilización, el programa liberalizador es contemplado en un artículo de Solidaridad Obrera desde esta perspectiva de ahondamiento en una situación colonial. Sin poder prever tampoco sus efectos a largo plazo ni el concurso de otros factores, el Plan era valorado como "presagio de una catástrofe" por la disminución del poder adquisitivo y por los desequilibrios en la balanza de pagos que sucederían a la devaluación y a la inflación, por encarecerse las importaciones y los costos de producción. Un año después, en otro artículo que resumía la trayectoria económica del país desde la guerra, los problemas iniciales de penuria se explican básicamente por razones internas, por la situación privilegiada que alcanzaron, con los jerarcas del Estado, determinados grupos sociales, especialmente los terratenientes. Pero el programa de liberalización de los años cincuenta es percibido como el vehículo de internacionalización de la economía española, que, con las medidas de devaluación, llevaría a una subida de precios de los productos extranjeros. Por otro lado, las facilidades a la entrada de capital extranjero, especialmente en empresas con cargos políticos en los consejos de administración, permitirían la llegada de firmas inglesas, francesas y estadounidenses interesadas en el mercado europeo y en los bajos salarios españoles. Este argumento suponía el reconocimiento de que las multinacionales se regían ante todo por el criterio de la disminución de costos dentro de un mercado internacional cada vez más integrado. También abundaba en la trascendencia de los contactos políticos de tales entidades empresariales en los países en que se ubicaban.

\section{EVOCACIÓN DE LAS EXPERIENCIAS REPUBLICANAS \\ Y PROGRAMAS ECONÓMICOS EN LOS AÑOS CUARENTA}

Si bien durante los años cuarenta escasean en el exilio los estudios generales sobre la economía española, dos temas adquieren relevancia en algunos encuentros: la evocación de las experiencias en los años treinta y la programación económica y social para el momento del regreso. Con ánimo de presentar 
exponentes destacados, en este apartado se valoran al gunas manifestaciones de tales preocupaciones.

En septiembre de 1939, el palacio de Bellas Artes de la ciudad de México acogía una serie de conferencias de destacados ingenieros agrónomos implicados en las experiencias de los años treinta. Algunas de ellas fueron publicadas después en revistas mexicanas. El que fue director del Instituto de Reforma Agraria (IRI) en gran parte de su largo andar, Adolfo Vázquez Humasqué, seguía en su conferencia, aparecida en Trimestre E conómico, la trayectoria legislativa durante 1931-1936. ${ }^{19}$ Este autor defendía el carácter ecléctico de la Ley de Reforma Agraria de septiembre de 1932, si bien juzgaba que el grupo de diputados "agrarios" había logrado limitar su alcance. También insistía en la interrupción operada en noviembre de 1933, tras el giro electoral, y en la reanudación del proceso - contemplando con fuerza el rescate de bienes comunales- desde el triunfo del Frente Popular en febrero de 1936.

En otra publicación, Revista de Economía y Estadística, se reprodujo la disertación de J osé Luis de la Loma, que analizaba la evolución del sector agrario en la zona republicana durante la guerra. ${ }^{20}$ Este autor, que había sido jefe de la Sección de Estadística, Economía y Política Agraria del Ministerio de Agricultura, cel ebraba los cauces oficiales imprimidos sobre la acción colectivizadora que de forma espontánea se produjo tras el levantamiento. No sólo consideraba contraproducentes varias de las iniciativas, por aspectos como la falta de preparación de algunos gestores y la supresión de especializaciones profesionales, sino que, al estilo de investigaciones posteriores, ${ }^{21}$ entendía que al gunas entidades habían seguido comportamientos neocapitalistas mediante la contratación de asalariados de zonas próximas. J osé Luis de la Loma también comentaba el obstáculo que significaron las limitaciones técnicas y financieras para importar abonos.

Todavía en 1941, el Trimestre E conómico reproducía la conferencia que sobre la evolución del crédito hasta los años treinta pronunció J osé María Dorronsoro, que había sido director general de Agricultura e inspector técnico del Banco Hipotecario de España. ${ }^{22}$ Tras un análisis histórico de la insu-

19 Adolfo Vázquez Humasqué, “EI problema agrario español”, en Trimestre E conómico, México, núm. 27, octubre-diciembre de 1940.

20 J osé Luis de la Loma, "Los problemas agrarios planteados durante la guerra española", en Revista de Economía y Estadística, México, noviembre-diciembre de 1939.

21 Walter L. Bernecker, Colectividades y revolución social. El anarquismo en la guerra civil española, 1936-1939, Barcelona, Crítica, 1982, p. 260.

22 J osé María Dorronsoro, “El crédito agrícola en España”, en TrimestreE conómico, núm. 28, México, enero-marzo de 1941. 
ficiente capitalización agraria y del escaso desarrollo del crédito, concentraba su interés en las dificultades para crear un Banco Nacional Agrario durante la República, destacando, como han hecho algunos estudios posteriores, ${ }^{23}$ la oposición de la banca privada y semiestatal. Durante la guerra, tanto el Instituto de Reforma Agraria como el Servicio Nacional de Crédito Agrícola se habían mostrado incapaces de responder al número de demandas crediticias del campesinado y de sus organizaciones.

De la trascendencia que en el exilio siguió ofreciéndose al sector agrario da fiel idea su tratamiento en la primera reunión de profesores universitarios, en La Habana, a fines de septiembre y principios de octubre de 1943. Este encuentro, a la vez que reforzó la cohesión de parte de la oposición, permitió perfilar propuestas que se esperaban poder aplicar pronto, una vez demolido el régimen franquista tras la prevista derrota del Eje. Republicanos y socialistas debatieron un programa que recuperaba el de la Segunda República, incorporando nuevas consideraciones teóricas como las derivadas del keynesianismo.

Los puntos que presentó el socialista Fernando de los Ríos en la capital cubana prolongaban, en particular, sus líneas tradicionales desde décadas antes, ${ }^{24}$ y serían el alma del sucinto programa agrario que él mismo redactó para su presentación por el primer gobierno en el exilio, al constituirse en el palacio de Gobierno de la ciudad de México, en noviembre de $1945 .{ }^{25}$ En él, además del modelo de reforma de septiembre de 1932, sugería varias medidas técnicas para aumentar la productividad y armonizar el desarrollo de los distintos sectores primarios. Con el Instituto de Reforma Agraria, proponía un Instituto F orestal que interviniera en la conservación, ordenación y explotación de masas arbóreas, y un Instituto de Biología Vegetal y Animal que extendiera la investigación y su aplicación a la agricultura. Su interés se deslizaba al impulso del regadío, del crédito, de la artesanía e industria domésticas, de la enseñanza y capacitación agropecuarias, de las cooperativas y formas colectivas de explotación, y de la obtención nacional de abonos. Al estilo de la obra que él mismo alentó desde el Ministerio de J usticia, seguía señalando la necesidad de una protección legislativa sobre arrendatarios y jornaleros, incluyendo facilidades a los primeros para acceder a la propiedad y seguro de paro para los segundos. Y como otros agraristas del exilio, también recogía

23 Leandro Benavides, La política económica en la II República, Madrid, Guadiana, 1972, pp. 101-103.

24 Paloma Biglino, El socialismo español y la cuestión agraria, 1890-1936, Madrid, Ministerio de Trabajo y Seguridad Social, 1986, pp. 234-237.

25 J avier Rubio, La emigración dela guerra civil de 1936-1939. Historia de éxodo que se pro duce con el fin de la II República española, vol. III, Madrid, San Martín, 1977, pp. 1004-1021. 
las posibilidades que en esas transformaciones abría el rescate de bienes comunales.

El papel general del sector agrario quedó remarcado en la ponencia que J osé de Benito y J ulián Alienes, profesores de derecho, leyeron en la sesión tercera, presidida por el ex ministro republicano Mariano Ruiz Funes, bajo el título "Reconstrucción, planificación y progreso económico". Estos autores no dudaban en considerar como dos principales rémoras del desarrollo económico español la estructura de la economía agraria y la dimensión alcanzada por el aislamiento del país. Contra el problema agrario, a los programas distrib u i d or y técnico agregaban medidas que estabilizaran los ingresos rurales -y así, la capacidad adquisitiva - y el desarrollo de sectores complementarios como los transportes, destacando la ampliación y electrificación del ferrocarril. En el sector externo, preconizaban el estímulo de la demanda internacional de la divisa española, la corrección de las fluctuaciones de la balanza de pagos y la ampliación del tonelaje mercante. En la liquidación de la deuda exterior, las propuestas de estos dos profesores reflejaban el gran error que en las previsiones de regreso cometían tantos exiliados: estimaban que tal objetivo sería pronto posible, una vez abatido el régimen franquista, si se vinculaba el problema al concierto de indemnizaciones de los países europeos, puesto que España podía considerarse la "primera víctima europea de la opresión totalitaria" y se encontraba en situación de dependencia dentro de la nueva "economía nacional-socialista". En coincidencia con las líneas iniciadas en algunos países desde los años treinta, reforzadas durante la coyuntura bélica y que continuarían con vigor después, estos autores también defendían una creciente intervención del Estado o nacionalización, en su caso, en los sectores bancario, transportes, seguros, minas, energía eléctrica e industria pesada.

J ulián Alienes también es el autor del apéndice que a modo de conclusiones cerraba el libro que recogió las ponencias de este encuentro en La Habana. En él, este autor llegaba más lejos en su análisis teórico sobre la importancia de los cambios agrarios y de la apertura para el desarrollo económico. En lo que consideraba un sistema "cuasi-autárquico" no para referirse al periodo iniciado bajo el régimen franquista, sino como trayectoria general desde décadas antes, J ulián Alienes descubría un predominio de exportaciones de productos agrarios de calidad y minerales fundamentales, así como una insuficiencia manifiesta de importaciones de insumos industriales. Ese aislamiento relativo habría aumentado la dependencia de la industria respecto a una agricultura que, bajo fuerte protección y con peso de los latifundios, se había mostrado menos dinámica que en otras partes de Europa. Con estas condiciones agra- 
rias y con este débil desarrollo industrial, al implicar inadecuada capitalización, desigual distribución del ingreso y altos costos de producción, habían resultado bajas la propensión a invertir y el "quantum" de consumo por persona. Altos precios agrícol as e industriales aparecían como lógico corolario de esas condiciones, disminuyendo la competitividad externa. De esta manera, los cambios agrarios — gl obales, no sólo del régimen de propiedad- aparecen como condición para lograr un mayor equilibrio interior y garantizar una economía nacional más competitiva, que hiciera posible el desarrollo del comercio exterior sobre bases más progresivas y rentables. Del aumento del nivel de vida derivarían un incremento de los ingresos y de la propensión a consumir y a ahorrar que estimularían tanto las industrias de bienes de consumo como las de bienes de producción. J ulián Alienes se refería asimismo, en general, a varias medidas sociales que, aparte de comulgar con "Ios finalismos económicos fundamentales de la Carta del Atlántico", tenían similar virtualidad para el estímulo de la demanda que las aplicadas en el sector agrario. El eco de los planteamientos keynesianos lo llevaba también a considerar necesaria la intervención del Estado, bien socializando las inversiones o cooperando con la iniciativa privada, para mantener una relación conveniente entre la inversión en bienes de producción y la renta total nacional.

En general, si se exceptúa el caso de los anarquistas, para quienes toda forma de intervencionismo dentro de esquemas capitalistas no tenía otra virtualidad sustancial que la de mantener las estructuras, los programas entre los exiliados españoles mantienen parcelas importantes de actuación para el Estado. En consonancia con su trayectoria ideológica y, pronto, con la práctica que en varios países europeos favorecieron sus propias tendencias, comunistas y socialistas preconizaban formas distintas de nacionalización. Los republicanos habían defendido también formas de economía mixta, aunque las posiciones eran diversas: para Gordón Ordás, el desarrollo de la empresa pública debía ser comedido, a fin de no afectar el de la privada. Tampoco entre los socialistas las soluciones eran únicas. Una propuesta singular fue la ofrecida por Indalecio Prieto en una muy divulgada disertación próxima al 10. de mayo de 1945, reproducida y comentada en sucesivos números de Ade lante. En ella, el líder socialista defendía un programa particular de "socialización de tierra, mar y aire", que hacía del municipio la célula básica de gestión en los ámbitos agrario, forestal, pesquero y del suel o urbano, mientras consideraba más apropiada la gestión privada en la banca y en la industria. Indalecio Prieto reservaba al Estado ámbitos como la enseñanza, las obras públicas, la seguridad social, el crédito público y, por su importancia en las exportaciones 
y por la desigual dotación del territorio, la extracción de minerales. En las diversas tareas de gestión, el líder socialista confiaba, en fin, en la colaboración y delegación de funciones en entidades sindicales, en instituciones locales diversas y, en campos como el transporte aéreo, en empresas privadas.

Por su carácter también singular, y porque a la vez incorpora consideraciones sobre la economía española de posguerra, interesa de ese mismo año, 1945, el proyecto de "reconstrucción" que Eusebio C. Carbó, adalid del anarcosindicalismo español en México, presentó mediante un amplio estudio. ${ }^{26}$ Bajo una profunda óptica filosófica de base, este autor concentraba su mayor interés en explotar a fondo los potenciales recursos del país y extender un modelo de desarrollo autóctono que redujera al máximo sus conexiones con el exterior. Este enfoque no guarda más semejanzas que las meramente formales con el esquema autárquico del franquismo, puesto que la búsqueda de autosuficiencia se prevé dentro de estructuras socializadas y responde a motivaciones distintas: se trata de asegurar viabilidad a un programa revolucionario que toparía con fuertes resistencias exteriores.

En el primer capítulo, Eusebio C. Carbó observa el problema fundamental que en la economía española de posguerra significaba la carga de la deuda con los países de los recién abatidos regímenes fascistas. Su incidencia ha sido confirmada - aunque con un peso menor - en estudios recientes como los ya citados de A. Viñas y J . Catalán. Tras rechazar las estimaciones de un informe del ministro español de Hacienda, aunque celebrándolo por suponer un reconocimi ento explícito de esa deuda, E usebio C. Carbó denunciaba las dádivas y las partidas exportadoras que absorbían las necesidades de compensación. Su juicio respecto al desembol so a Alemania era contundente:

Tampoco puede confesar el ministro que la valija diplomática alemana salía decenal mente abarrotada de oro, en monedas antiguas, en lingotes, en objetos de arte, y de piedras preciosas, cuyo val or no fue jamás objeto de un asiento en la contabilidad, ni fue calculado por nadie. Habrá medio de probarlo cuando se pueda volver a España. (p. 24).

En otros capítulos, E usebio C. Carbó expl ora los condi cionantes que se interponían limitando el potencial económico español, sobre todo su escasa capacidad para influir en el modelo de relaciones comerciales y posibilitar el aumento de exportaciones y la disminución de importaciones. Contra las ventas en el exterior, actuaría el interés de economías más potentes en contener

26 Eusebio C. Carbó, Reconstrucción de España. Sus problemas económicos, políticos y morales, México, D.F., Prometeo, 1945. 
la salida de mercancías para mantener los precios internacionales. Además, la exportación de bienes de primera necesidad coincidía con carencias en el interior e importaciones de productos que podrían elaborarse en el país por encima incluso de esas necesidades. Lejos de la tradicional decantación hacia el sector agrario que habían presentado numerosos pensadores anarquistas, ${ }^{27}$ el programa de Eusebio C. Carbó se extendía, entre otros puntos generales, hacia la explotación máxima del carbón y demás fuentes propias de energía, la extensión de la electrificación rural, el desarrollo del ferrocarril y una industrialización que permitiera aprovechar in situ las materias primas. Estas afirmaciones se repiten en un discurso que hace de la explotación máxima de las posibilidades de autoabastecimiento una premisa para el desarrollo de la revolución, por mitigar los efectos de un posible bloqueo exterior. En el análisis, no faltan consideraciones típicamente anarquistas sobre el sindicato, el municipio y la autonomía individual como células de decisión y de actuación que una planificación superior debía respetar.

\section{LAS CONFEREnCIAS de GORdón ORdÁs}

Si bien en la prensa republicana española de México no aparecen críticas sistemáticas al intervencionismo franquista, sí contamos con un análisis pormenorizado de uno de los líderes de esta tendencia desde su cara más moderada, Félix Gordón Ordás. Este político, que habría de ser presidente del gobierno en el exilio durante casi toda la década de los años cincuenta, había adquirido una fuerte formación económica que, con amplia base en publicaciones y estadísticas españolas, lo llevó a disertar sobre la evol ución económica y financiera en una conferencia en el Ateneo Español de México, en junio de 1949. En otras dos ocasiones, en junio de 1950 y en agosto de 1951, siguió reflexionando y completó su visión sobre la trayectoria seguida hasta el momento de cada disertación. En la publicación final de estas conferencias, amplió su análisis. ${ }^{28}$

En primer lugar, este autor también ofrece algunas consideraciones generales sobre la evolución económica anterior. Frente a la visión catastrofista que de la economía del primer tercio del siglo xx había ofrecido J osé Antonio Suanzes en su defensa del presupuesto en las Cortes, en diciembre de 1947, ${ }^{29}$

27 Xavier Paniagua, La sociedad libertaria. Agrarismo e industrialización en el anarquismo español, 1930-1939, Barcelona, Crítica, 1982.

28 Félix Gordón Ordás, Al borde del desastre Economía y finanzas de España (1939-1951), México, Impresora Guitian, 1952.

29 Este catastrofismo fue desplegado por el ministro de Industria y Comercio a través de numerosas intervenciones, Pablo Martín Aceña y Francisco Comín, “El estado en la industrialización 
Gordón Ordás planteaba un panorama radical mente distinto, celebrando diversos aspectos del periodo republicano. A su juicio, la actividad económica durante esta etapa había topado con obstáculos como la conflictividad social, las amplias expectativas entre sectores desposeídos, la desconfianza empresarial ante el clima de reformas y la evasión de capitales. Pero a la vez, val oraba una serie de aspectos positivos: tendencia a la estabilidad de los precios, aumento del mercado interior por la subida de jornales, medidas contra el paro forzoso, relativo mantenimiento del comercio exterior $y$, entre otros el ementos, una mejora de las liquidaciones presupuestarias, con déficits moderados y contención de deuda pública. Al estilo de otros autores del exilio y obviando tensiones internas del colectivo, este político también entraba a justificar en sus conferencias unas iniciativas especial mente polémicas de los gobernantes en la zona republicana: el empleo de reservas metálicas para financiar la guerra y el asentamiento posterior de los exiliados. Veía tal uso como única salida cuando se carecía de otras vías y de ayuda exterior.

Al observar el periodo autárquico, Gordón Ordás se detiene, entre otros temas, en los problemas de financiación y en los efectos de la intervención. Me diante tales análisis, este autor es uno entre los consultados que más explícita y exhaustivamente cuestiona, aparte de la práctica reguladora, la viabilidad del sistema autárquico. Su defensa de la liberalización abarca tanto el plano exterior, principalmente al clamar por la apertura comercial y por una "controlada" llegada de capital, como el interior, demandando la supresión de las fuertes regulaciones sectoriales.

En el desarrollo del Instituto Nacional de Industria (INI), Gordón Ordás evocaba un referente distinto al tantas veces recordado I nstituto per la Riconstruccione Industriale (IRI) italiano: el Instituto Argentino de Promoción de Intercambios, que, sin embargo, entre otras funciones, actuaba en la distribución exterior de cereales y carne. Pero mientras en este otro organismo distinguía una adecuada base financiera precisamente por esa función distribuidora, el insuficiente capital del INI constituiría una de las razones del aumento constante de la deuda pública. El delirio autárquico y la atracción psicológica de la técnica a gran escala -en expresión casi literal de este autor-

española de posguerra: el Instituto Nacional de Industria", en Prados de la Escosura y Zamagni (eds.), op. cit., 1992, pp. 433-434. Tal postura formaba parte, en el fondo, de un amplio abanico doctrinal y propagandístico que incluía similares procesos de descomposición política y moral bajo coordenadas liberales. En este discurso de diciembre de 1947, Suanzes se había referido de forma genérica a la agricultura poco "racionalizada", al proceso de industrialización "pernicioso y desordenado", al descenso de índices de producción de materias básicas y a la "crisis técnica y económica" de los sistemas de transportes. 
habían alimentado un plan de realizaciones para 1949 ausente de consideraciones financieras. Esta denuncia sobre la desatención a los costos, que repite este autor en más de una ocasión, se encuentra próxima a los juicios desarrollados por investigadores posteriores sobre el hol ding estatal. ${ }^{30}$

A los problemas de liquidez de las empresas, azuzados - para este autorpor la carga financiera que implicaba la emisión de acciones y de obligaciones con altos tipos de interés, se sumaban las dificultades para adquirir materias primas del exterior, renovar la maquinaria y dotarse de recursos energéticos. Aunque no existieran problemas de liquidez, la disponibilidad de insumos se mostraba precaria en un marco institucional caracterizado por las restricciones, los cupos oficiales, las licencias de importación y la organización de turnos de actividad. Tales el ementos habían originado una maraña de corrupciones, una clara insuficiencia de divisas, una dicotomía entre el mercado oficial y el clandestino de primeras materias y, en definitiva, un caos global en el sistema productivo. Los bajos niveles salariales y la baja formación profesional también repercutían -en una amplia valoración del autorsobre la baja productividad del trabajo.

Al descender en su análisis a los distintos subsectores, Gordón Ordás insistía en los estrangulamientos que en cada caso se manifestaban. En el textil algodonero, la falta de fibra, maquinaria y energía eléctrica coincidía con la insuficiencia de mercados remunerativos. La extracción minera, con signos de agotamiento, exigía nuevos procedimientos. La insuficiencia de la producción siderúrgica, que constituía en sí misma una limitación fundamental para varios subsectores, debía combatirse aumentando el carbón coquizable, la chatarra y el hierro disponibles, así como mejorando la especialización de la mano de obra. Subsectores de impulso reciente, como las fibras sintéticas, los abonos artificiales o los automóviles, se enfrentaban a deficiencias similares en el aprovisionamiento de insumos. Así, la prevista creación de Sociedad Española de Automóviles de Turismo (SEAT) levantaba dudas en él no sólo por la fuerte dependencia de FIAT, sino también por la penuria de hierro, acero y caucho en la situación de aislamiento.

Gordón Ordás interpretaba el fracaso de varias de las iniciativas estatales para promover algunos subsectores industriales como resultado de los objetivos autárquicos y la ausencia de consideraciones financieras. Para él, el desarrollo industrial requería el estímulo previo de cuatro ámbitos: energía eléctrica, carbón, hierro y acero, y transportes. Las restricciones eléctricas

30 Por ejemplo, Donges, op. cit., 1976, pp. 42-43, y Pablo Martín Aceña y Francisco Comín, INI: 50 años deindustrialización en España, Madrid, Ministerio de Educación y Ciencia, 1991, p. 31. 
debían combatirse mediante planes eficaces, no dispersos, que se concentraran en las obras más adelantadas o aconsejables. El déficit de carbón debía superarse mediante la ampliación de las importaciones, la especialización y mejor uso de la mano de obra, la mejora de calidades y la mayor vertebración de las zonas mi neras y centros de consumo. El aumento de la producción siderúrgica exigía las medidas señaladas más arriba. ${ }^{31}$ En los transportes, Gordón Ordás se refería a la necesidad de planes realistas de reforma y el ectrificación de la red ferroviaria, cuyas expectativas al crearse Red Nacional de Ferrocarriles Españoles (Renfe) no juzgaba complacidas.

\section{DEPENDENCIA Y LIBERALIZACIÓN EN TEXTOS \\ DE LOS AÑOS CINCUENTA}

Aparte del trabajo de Gordón Ordás, en la década de los años cincuenta aparecen otros análisis en México, de la mano de autores exiliados, que suponen aproximaciones generales al conjunto de la economía española. La etapa muestra evidentes diferencias con la de la década interior: Ios planteamientos autárquicos y el fuerte intervencionismo ceden en un proceso de paulatina apertura y liberalización. J unto a algún estudio enmarcado en las mismas tesis de dependencia de los periódicos comentados más arriba, la mayor parte de los trabajos detectados, aunque se aproximan en al gunas de sus críticas puntuales, se alejan de esa concepción general. En este caso, los autores centran su preocupación en las relaciones comerciales, en el desarrollo agrario e industrial -a menudo, sin énfasis en cambios estructurales profundos- y en la intervención del Estado, al que se atribuye gran autonomía.

Entre los textos que siguen planteamientos de dependencia, el del comunista Felipe M. Arconada aparece en 1951, ${ }^{32}$ antes que el de Gordón Ordás, por lo que todavía no se ha emprendido el proceso de liberalización económica que precisamente ese mismo año anunció el nuevo equipo de gobierno en España. En este análisis, Felipe M. Arconada, dirigente significativo del PCE en México y hermano de un conocido escritor de novela social, traza un am-

31 Resultan especialmente próximas las valoraciones que sobre los problemas en el sector siderúrgico han realizado Manuel González Portilla y J osé María Garmendía, La posguerra en e País Vasco. Política, acumulación, miseria, Itxaropena Donostia, 1988; Manuel González PortiIla, "EI País Vasco y la posguerra: crecimiento económico y especialización industrial", en M. Tuñón de Lara (coord.), EI primer franquismo. España durantela segunda guerra mundial, Madrid, Siglo Xxı, 1989; y J . Catalán, op. cit., 1995. Estos autores también se refieren a la escasez de materias primas, chatarra y energía, así como a la insuficiencia de una mano de obra capacitada y estimulada.

32 F elipe Muñoz Arconada, España, col onia yanqui, México, Nuestro Tiempo, noviembre de 1951. 
plio examen sobre las conexiones que la estructura productiva española, en términos de dependencia, estaba desarrollando respecto a Estados Unidos antes de que se firmaran los conocidos pactos. La obra se inscribe claramente en las pautas generales comentadas en los artícul os de España Popular. Un informe del ala más radical, contraria al prietismo, de la Unión General de Trabajadores (UGT), en junio de 1949, se expresaba en términos parecidos a este autor. En este informe, sin embargo, quizá por ser anterior en más de dos años, con el proceso aún en ciernes, se consideraba esa línea de subordinación no como la absolutamente dominante, sino como la principal de una serie amplia de vinculaciones exteriores. El político comunista denunciaba la misma fórmula fundamental de las multinacionales que veíamos en un texto anarquista, de cronología posterior, al declarar que el capital estadounidense se instalaba en España atraído por la baratura de la mano de obra y por el potencial del mercado europeo.

A lo largo de una parte sustancial del libro, Felipe M. Arconada enumera, explica y muestra mediante casos concretos distintos tipos de vías en ese dominio colonial, que no se agotan, aunque sí encuentran su amplio carril central, en esa entrada de capitales. Varias empresas habrían pasado de manos alemanas a estadounidenses — cifraba 67 hasta el momento-, aunque se mantenían testaferros germánicos y españoles en sus consejos de administración. Como sectores destacados de esa transferencia, señalaba el caucho y la electricidad. A la vez, habían sido desplazados otros intereses imperialistas, principalmente ingleses y franceses, en sectores como el minero, el siderometalúrgico y el químico. Con el desplazami ento directo, también se había logrado otro indirecto mediante el predominio al canzado en trusts y consorcios internacionales presentes en España. El capital estadounidense, además, había adoptado posiciones en empresas del conglomerado industrial-militar del INI, que gozaban de ventajas fiscales y de otros tipos. Como principales sectores, señalaba aquí el petrolero y algunas ramas de transportes. Al denunciar también la alianza con la oligarquía financiera española, introducía a las multinacionales estadouni denses entre las responsables de la concentración y la eliminación de concurrentes. Con ello, este autor entraba de lleno en Ios planteamientos teóricos que unían imperialismo y oligopolización. Además de la penetración del capital en sectores diversos, otras vías contribuían para Felipe M. Arconada a acrecentar ese dominio exterior: el control sobre los precios mundiales, fuerte en minerales estratégicos, los acuerdos de cesión de patentes, diseños y marcas, y la intervención de la Misión Militar Norteamericana en el Consejo Ordenador de Minerales Estratégicos. 
El interés de las tesis de estos trabajos para el análisis historiográfico actual estriba en que, por su cronología, se orientan sobre unas vinculaciones y relaciones ya intensas de forma previa a las fechas que de manera común se consideran de inicios de la liberalización y de ruptura del model o autárquico. De este modo, pueden alumbrar sobre la incubación de unas condiciones básicas para el cambio de ese marco institucional, paralelo al que se forjó en las relaciones políticas exteriores ya desde los últimos años cuarenta. El contraste de estas tesis es manifiesto con las visiones que, al fijarse en las limitaciones impuestas por la Ley de Ordenación y Defensa de la Industria Nacional de 1939, consideran que sól o las medidas de apertura emitidas veinte años después abrieron las puertas de manera significativa a la inversión exterior. ${ }^{33}$ Sin embargo, autores como R. Tamames o M.J . González, aunque también coinciden en subrayar la importancia de la restricción legislativa al capital extranjero, anotan, sin embargo, posibilidades especiales en la introducción del mismo: el primero, al destacar cómo las limitaciones para transferir beneficios fuera y la inconvertibilidad de la peseta estimulaban la reinversión dentro;34 el segundo, al recordar cómo la ley de 1939, aunque restringía la participación del capital extranjero en una empresa al 25\%, permitía superar tal porcentaje en proyectos industriales de gran interés, bajo discrecionalidad política, a la vez que los tratados de comercio marcaban condiciones específicas para las inversiones de cada país. ${ }^{35}$

El resto de los ensayos generales consultados de los años cincuenta muestran mayores similitudes con las conferencias de Gordón Ordás que con el estudio de Felipe M. Arconada. Esto es así, especialmente, en el trabajo de Máximo Muñoz, de publicación coetánea al libro de aquél y con citas expresas de sus tesis. ${ }^{36}$ Como Felipe M. Arconada, y bajo similar petición de un cambio de régimen como condición necesaria, este autor socialista se refiere a las limitaciones que en el crecimiento implicaban las directrices presupuestarias, las deficiencias en las infraestructuras de comunicaciones y la insuficiencia de insumos, destacando las dificultades de renovación del material. También se detiene en al gunas cuestiones donde la conexión entre lo político y lo econó-

33 En su análisis sobre los pactos de 1953, A. Viñas no negaba cierta presión de empresarios estadounidenses para normalizar relaciones, pero mi nimizaba su al cance (op. cit., 1981, pp. 3334). En el estudio de Clavera y otros, las peticiones de liberalización desde Estados Unidos en los pactos de 1953 tenían menor importancia relativa que los objetivos estratégicos y militares (op. cit., 1973, II, p. 71). J . Catalán apunta, en todo caso, un aumento de la inversión europea en los años cincuenta (art. cit., 1995, pp. 131-132).

34 Tamames, op. cit., 1969, pp. 732-733.

35 González, op. cit., 1979, pp. 217-218.

36 Máximo Muñoz, Tragedias y derroteros de España, México, 1952. 
mico en el plano internacional parecía clara a simple vista: primero, para culpar a las finanzas extranjeras de haber bloqueado, durante la guerra, el cambio de la peseta oficial, de la zona republicana, en beneficio de la ilegal, impulsando así la salida de oro como único medio de pagar importaciones y financiar la actuación bélica. En segundo lugar, el autor responsabiliza a Franco de no haber posibilitado, por mantener el régimen dictatorial, la ayuda de la United Nations Relief and Rehabilitation Administration -Administración de Ayuda y Reconstrucción de Naciones Unidas- (UNRRA) y del Plan Marshall, necesaria para la reconstrucción.

Las demás aproximaciones datan ya de fines de los años cincuenta, cuando el proceso de liberalización se muestra muy avanzado. Todos ellos manifiestan similar énfasis en el proceso de industrialización y en la diversificación de relaciones comerciales como vías para acabar con el atraso, mejorar la balanza de pagos y aumentar el nivel de vida. Antonio Rojas García, en un examen presentado como trabajo de licenciatura, ${ }^{37}$ explica el desequilibrio comercial por el bajo índice industrial, considera insuficiente - aunque no negativo- el proteccionismo como resorte de crecimiento, y resalta la inadecuación de la producción agraria para cubrir el consumo interior en sectores para los que, sin embargo, existían condiciones favorables. Al considerar asimismo fundamental el objetivo de contener la inflación, su propuesta industrializadora se centraba en el apoyo inicial a los sectores ligeros, menos necesitados de ayuda pública que los pesados. Del mismo año que el anterior trabajo data una reflexión heterogénea de un escritor, Antonio Márquez, que se aproximaba en uno de sus capítulos a los aspectos económicos. ${ }^{38}$ Este autor, que permaneció dos años en España antes de publicar este libro de impresiones más que de análisis, consideraba no sal dada la ruptura del intervencionismo de los años cuarenta y sol icitaba ponerse abierta y decididamente dentro de la economía liberal. Advertía, a la vez, sobre la necesidad de no caer en dependencias externas y de la conveniencia de expandir el comercio exterior con todos los países potenciales, al margen de reticencias políticas de ningún tipo.

También la obra de Ramón Ramírez es producto de un viaje a España, que le permitió recopilar datos estadísticos y publicaciones diversas. ${ }^{39}$ Él había estado al frente de la sección de Enseñanza de la UGT, la central sindical socialista, pero adquirió en México formación economista y desarrolló su labor en el marco del Instituto de Investigaciones E conómicas de la UNAM. Su tra-

37 Antonio Rojas García, España (Semblanza Económica), México, 1958.

38 Antonio Márquez, Sobre la situación de España, México, Libro-Méx, 1958.

39 Ramón Ramírez Gómez, Situación económica y social de España, México, 1959. 
bajo se inspiraba directamente en las conferencias de Manuel de Torres en el Ateneo de Madrid, a fines de 1955, que habían originado el conocido libro J uicio de la actual política económica española. Como él, ${ }^{40}$ este autor definía la industrialización como proceso dialéctico, no lineal, que implicaba el desarroIlo armónico y coordinado, con el propio sector industrial, de ámbitos como las infraestructuras, la actividad agraria, los transportes y el crédito. También como él ${ }^{41}$ y como tantos otros autores en el exilio, contemplaba la necesidad de una actuación estatal dirigida a evitar un fuerte desarrollo de monopolios en el proceso. Consideraba insuficiente tanto la inversión privada como la pública, mediante el INI. A la vez, juzgaba necesario luchar contra las presiones inflacionistas, que él relacionaba en esos momentos no tanto con el alza salarial como con un aumento de la circulación fiduciaria superior a la de los bienes reales y con el déficit de la balanza de pagos. En efecto, Ramón Ramírez descubría una espiral en las relaciones entre inflación, comercio exterior y producción: la tendencia al cista de los precios hacía disminuir las exportaciones, pero a la vez, al no obtener las divisas necesarias para importar insumos, ascendían los costos de producción y así los precios. Este autor, al analizar los pactos de ayuda económica y militar con Estados Unidos, también apuntaba unos efectos inflacionistas y minimizaba su incidencia en el crecimiento: tales ayudas, por su carácter básicamente militar, supondrían nuevas cantidades de dinero sin un correlativo desarrollo. Los efectos deflacionistas de la llegada de productos de consumo no compensaban, por su importancia relativa menor, aquellos otros de signo inflacionista. En el trabajo de J. Clavera y otros, tales ayudas habían supuesto una pequeña inyección de oxígeno y la reserva de un contraval or en pesetas tendría un efecto estabilizador ${ }^{42} \mathrm{~A}$. Viñas, en cambio, coincidiendo con R. Ramírez, ha insistido en la preeminencia del interés militar en las ayudas, descartando a la vez una funcionalidad deflacionista en unas reservas de pesetas nuevas, surgidas a impulsos de la propia ayuda exterior. ${ }^{43}$

\section{CONCLUSIONES}

Más que en sus val oraciones sobre los efectos del intervencionismo, los planteamientos en el exilio sobre la economía española difieren en su modo de afrontar las relaciones exteriores. Aunque de manera muy simplificada, el

40 De Torres, op. cit., 1956, pp. 175-189.

41 I bíd., pp. 83-84.

42 Clavera y otros, op. cit., 1973, vol. II, pp. 64-71.

43 Viñas, op. cit., 1981, pp. 251-275. 
espectro de textos abarcado puede agruparse en dos categorías. En primer lugar, el de aquellos que, desde pretensiones rupturistas fuertes, aunque distintas, consideraban que las vinculaciones externas de la economía española, bajo la égi da franquista, significaban una nueva manifestación de dominio colonial. El capital extranjero, principalmente el estadounidense, en alianza con el capital bancario interior y los altos cargos políticos, interpenetrados, iría acaparando posiciones en numerosos sectores industriales desde la segunda mitad de los años cuarenta, lo que vendría a producir o exacerbar desajustes económicos y sociales. Un segundo tipo corresponde al conjunto de textos que, sin cuestionar de forma global las estructuras ni dar tanto protagonismo a las presiones exteriores, comentan determinados problemas en las relaciones económicas, sobre todo en el equilibrio de la balanza de pagos.

Aunque todos coinciden en señalar la necesidad de un cambio de régimen, la variedad de concepciones sobre las posibilidades de autonomía del poder político dentro de estructuras capitalistas y las distintas aspiraciones finales impiden, lógicamente, concordar también en las valoraciones sobre el modo como convenía actuar en la esfera económica internacional. En cualquier caso, las propuestas gl obales en ese sentido suel en ser poco explícitas, incluso desde las posturas más rupturistas. Pero sí se repiten, en trabajos de signo distinto entre sí, peticiones sobre ruptura del marcado bilateralismo en las conexiones con Estados Unidos, ampliación geográfica de los intercambios al margen de simpatías políticas, necesidad de diversificación económica para modificar el modelo de relaciones comerciales, etc. $Y$ se debate, desde posturas diversas, sobre cuestiones comunes, como la incidencia de las exportaciones en el consumo interior o la conveniencia o no de una devaluación en determinadas coyunturas. Desde posiciones anarquistas, la búsqueda del máximo autoabastecimiento por el temor a la oposición y al bloqueo exteriores en una situación revolucionaria introducía matices especiales en la reflexión sobre estas cuestiones.

En el conjunto de textos, no resulta característica la visión de los años cuarenta en España como etapa de búsqueda de autarquía, o al menos apenas se incide en este aspecto si se exceptúan al gunas publicaciones de los años cincuenta, como la de Gordón Ordás. A. Viñas, aunque enfatiza la trascendencia de esta opción, tampoco descubre en el fondo una verdadera autarquía, al menos de manera pura. Al examinar los problemas de la reconstrucción española, en la órbita de la Segunda Guerra Mundial y con dificultades de abastecimi ento exterior, la búsqueda de autosuficiencia sería imposible, para este investigador, ya al margen de las voluntades reales: "Las condiciones 
objetivas dominantes contribuyeron a definir, pues, el límite de las ambiciones de la acción gubernamental exterior del arrogante Nuevo Estado, mantuvieron a España fuera de la contienda y acrecentaron la dependencia con respecto al entorno, a pesar de todas las proclamaciones de autarquía". ${ }^{44}$

Del mismo modo, en los textos del exilio, el fuerte intervencionismo no queda explicado por un posible interés en el autoabastecimiento y la reconstrucción, sino, sobre todo, por la voluntad de control que se extiende sobre las distintas esferas de actividad, incluyendo la agricultura, la industria y las relaciones económicas exteriores. ${ }^{45}$ Para aquellos autores que veían una nueva fórmula de dominio colonial, lejos de esa búsqueda de autarquía, dominarían unas políticas económicas subordinadas a capitalistas extranjeros y a la oligarquía financiera interior, que no entrarían en contradicción. El choque de intereses se produciría sobre todo, por el contrario, entre estos sectores y los pequeños y medianos empresarios y productores. La liberalización de los años cincuenta, tal como se estaba desarrollando, era para algunos de estos autores el camino hacia una integración capitalista más plena del país en condiciones de dependencia. Otros autores, con acentos liberales, cel ebran la apertura por entender que intensificaría el intercambio y así el crecimiento, aunque advierten sobre la conveniencia de diversificar tanto los productos como las áreas de interés comercial y establecer los controles oportunos en las entradas de capital. Existía, pues, en conjunto, una gran variedad de posturas que, si en el plano político de fondo coincidían, al menos, en sus críticas contra la dictadura, en el económico presentaban una diversidad amplia de tonos e incluso diferencias difíciles de conciliar. Esta variedad iba desde la proximidad, e incluso fuerte identificación con las posturas liberales que pulsaban dentro del régimen, hasta alternativas rupturistas que sugerían cambios profundos en las estructuras, en las directrices de intervención y en el model o de relaciones exteriores.

44 Viñas, op. cit., 1984, pp. 261-262. Más lejos Ilegaban J . Braña, M. Buesa y J . Molero en unas de las afirmaciones más atípicas dentro de la historiografía económica española sobre este periodo, al combinar el rechazo de la autarquía como horizonte deseable de la política industrial con la consideración de que durante estas décadas se asientan las bases estructurales del desarroIlo que sucedería en los años sesenta (EI Estado y el cambio tecnológi co en la industrialización tardía. Un análisis del caso español, Madrid, Fondo de Cultura Económica, 1984, p. 200).

45 Obsérvese una valoración en dirección similar por Braña y otros, en op. cit., 1984, p. 184. “De ahí que la intervención estatal no sea, en este contexto, una cuestión de carácter ideológico - la autarquía - sino una necesidad real de supervivencia social y política, tanto del régimen político que encarna el Nuevo Estado, como de las clases sociales que, victoriosas por la fuerza de las armas, lo sustentan". 


\section{APÉNDICE}

\section{PENETRACIÓN ESTADOUNIDENSE EN LA ECONOMÍA ESPAÑOLA DESDE LA SEGUNDA MITAD DE LOS AÑOS CUARENTA (SOBRE TODO, 1949-1951). ALGUNOS CASOS Y VÍAS PRESENTADOS POR FELIPE M. ARCONADA}

\begin{tabular}{|c|c|c|}
\hline Sectores & $\begin{array}{c}\text { Empresas } \\
\text { (Estados Unidos) }\end{array}$ & Vías de penetración y estrategias \\
\hline - Caucho & $\begin{array}{l}\text { - General Tire and Ruber } \\
\text { - Firestone } \\
\text { - B. F. Goodrich }\end{array}$ & $\begin{array}{l}\text { - Traspaso de empresas alemanas } \\
\text { - Conexión con oligarquía financiera } \\
\text { (J uan March) } \\
\text { - Diversificación: textil, plásticos, } \\
\text { calzado. }\end{array}$ \\
\hline $\begin{array}{l}\text { - Electricidad y produc- } \\
\text { tos electrónicos }\end{array}$ & $\begin{array}{l}\text { - Tel efunken } \\
\text { - Standard Electric-Westinghouse } \\
\text { - ITT } \\
\text { - General Electric } \\
\text { - Consolidated Electric and Gas of } \\
\text { New York }\end{array}$ & $\begin{array}{l}\text { - Traspaso de empresas al emanas } \\
\text { - Militares en consejos de adminis- } \\
\text { tración } \\
\text { - Predominio en trust internacionales } \\
\text { - Absorción de empresas españolas }\end{array}$ \\
\hline - Petróleo & & $\begin{array}{l}\text { - Participación en empresas del INI } \\
\text { (Emp. Nacional Calvo Sotelo, CEPSA) } \\
\text { - Conexión con oligarquía financiera } \\
\text { - Monopolio de suministro a CAMPSA } \\
\text { durante } 15 \text { años }\end{array}$ \\
\hline $\begin{array}{l}\text { - Sidero-metalurgia y } \\
\text { productos de metal }\end{array}$ & $\begin{array}{l}\text { - Steel Corporation } \\
\text { - Aluminium Company }\end{array}$ & $\begin{array}{l}\text { - Participación en empresas españolas } \\
\text { (ENDASA) } \\
\text { - Creación de filiales } \\
\text { - Desplazamiento de capital inglés en } \\
\text { industrias de armas } \\
\text { - Conexión con oligarquía financiera y } \\
\text { cargos políticos }\end{array}$ \\
\hline $\begin{array}{l}\text { - Transportes y comu- } \\
\text { nicaciones }\end{array}$ & $\begin{array}{l}\text { - General Motors } \\
\text { - cURTISS } \\
\text { - Marconi International }\end{array}$ & $\begin{array}{l}\text { - Participación en empresas, inclu- } \\
\text { yendo las del INI (como en SEAT, } \\
\text { mediante FIAT) } \\
\text { - Acuerdos de colaboración (Atlas } \\
\text { Diesel con Bazán) }\end{array}$ \\
\hline - Minerales & $\begin{array}{l}\text { - Anglo-American Corp. } \\
\text { - Banca Ladenburg Thalman }\end{array}$ & $\begin{array}{l}\text { - Desplazami ento de capital europeo. } \\
\text { - Partici paci ón en expl otaci ones de } \\
\text { mercurio, cobre, plomo, zinc. } \\
\text { - Predominio en trust y cartels (potasa) }\end{array}$ \\
\hline - Química & - Du Pont de Nemours & $\begin{array}{l}\text { - Desplazamiento de intereses britá- } \\
\text { nicos y franceses (dominio extranjero } \\
\text { en Unión E spañola de Explosivos) } \\
\text { - Conexión con ol igarquía financiera }\end{array}$ \\
\hline - Industrias de consumo & & $\begin{array}{l}\text { - Predominio en trust y consorcios } \\
\text { (Nestlé, U nilever, Libbey Owers, } \\
\text { etc.) } \\
\text { - Distribución de materia prima y pro- } \\
\text { ducto en textil algodonero catalán } \\
\text { y yute }\end{array}$ \\
\hline
\end{tabular}

FUENTE: Elaboración a partir de Felipe M. Arconada, España, colonia yanqui, México, Nuestro Tiempo, noviembre de 1951. 


\section{BIBLIOGRAFÍA}

- Aceña, Pablo Martín, y Francisco Comín, “EI Estado en la industrialización española de posguerra: el Instituto Nacional de Industria", en Leandro Prados de la Escosura y Vera Zamagni (eds.), El desarrollo económico en la Europa del Sur: España el talia en perspectiva histórica, Madrid, Alianza Universidad, 1992.

- Aceña, Pablo Martín y F rancisco Comín, INI: 50 años de industrialización en España, Madrid, Ministerio de E ducación y Ciencia, 1991.

- Barciela, Carlos, "Los costes del franquismo en el sector agrario: la ruptura del proceso de transformaciones", introducción a la segunda parte de R. Garrabou, C. Barciela y J .I. J iménez Blanco (eds.), Historia agraria de la España contemporánea. 3. El fin dela agricultura tradicional (1900-1960), Barcelona, Crítica, 1986.

- Barciela, Carlos, "La modernización de la agricultura y la política agraria", en Papeles de Economía Española, núm. 73, 1997.

- Benavides, Leandro, La política económica en la II República, Madrid, Guadiana, 1972.

- Bernal, A.M., "La modernización de la agricultura española”, en Papeles de Economía Española, núm. 73, 1997.

- Bernecker, Walter, Col ectividades y revolución social. El anarquismo en la guerra civil española, 1936-1939, Barcelona, Crítica, 1982.

- Biglino, Paloma, El socialismo español y la cuestión agraria, 1890-1936, Madrid, Ministerio de Trabajo y Seguridad Social, 1986.

- Braña, J ., M. Buesa y J. Molero, El Estado y el cambio tecnol ógico en la industrialización tardía. Un análisis del caso español, Madrid, Fondo de Cultura Económica, 1984.

- Carbó, E usebio C., Reconstrucción de España. Sus problemas económicos, políticos y morales, México, Prometeo, 1945.

- Catalán, J ordi, La economía española y la Segunda Guerra Mundial, Barcel ona, Ariel, 1995.

- __ "Reconstrucción, política económica y desarrollo industrial del sur de Europa, 1944-1953", en Leandro Prados de la Escosura y Vera Zamagni (eds.) El desarrollo económico en la Europa del Sur: España el talia en perspectiva histórica, Madrid, Alianza Universidad, 1992.

- _ _ "Sector exterior y crecimiento industrial. España y Europa, 19391959", en Historia Industrial, núm. 8, 1995.

- Clavera J ., J .M. Esteban, M.A. Monés, A. Montserrat y J . Ros Hombravella, Capitalismo español: dela autarquía a la estabilización (1939-1959), vol. I, Madrid, Cuadernos para el Diálogo, 1973. 
- De la Loma, J osé Luis, “Los problemas agrarios planteados durante la guerra española", en Revista de E conomía y Estadística, México, noviembre-diciembre de 1939.

- Díaz, Elías, Pensamiento español en la era deFranco (1939-1975), Madrid, Tecnos, 1983.

- Donges, J uergen B., La industrialización en España. Políticas, logros y pers pectivas, Barcel ona, Oikos-Tau, 1976.

- Dorronsoro, J osé María, “El crédito agrícola en España”, en Trimestre Eco nómico, núm. 28, México, enero-marzo de 1941.

- "El Congreso Sindical de la Tierra organizado por Falange", en España Popular, núm. 400, 28 de mayo de 1948.

- Fernández Roca, Francisco J avier, "Estrategias empresariales en una economía intervenida", en III Encuentro de Investigadores del Franquismo, Sevilla, enero de 1998.

- Garrabou, Ramón, “Políticas agrarias y desarrollo de la agricultura española contemporánea: unos apuntes", en Papeles de Economía Española, núm. 73, 1997.

- Gibaja Velázquez, J.C., Indal ecio Prieto y el socialismo español, Madrid, editorial Pablo I glesias, 1995.

- González, Manuel J esús, La economía política del franquismo (1940-1970). Dirigismo, mercado y planificación, Madrid, Tecnos, 1979.

- González Portilla, Manuel, "EI País Vasco y la posguerra: crecimiento económico y especialización industrial", en $M$. Tuñón de Lara (coord.), EI primer franquismo. España durantela segunda guerra mundial, Madrid, Siglo xxı, 1989.

- González Portilla, Manuel y J osé María Garmendía, La posguerra en el País Vasco. Política, acumulación, miseria, Itxaropena Donostia, 1988.

- Gordón Ordás, Félix, Al borde de desastre Economía y finanzas de España (1939-1951), México, I mpresora Guitian, 1952.

- “Informe del interior. La situación económica de Cataluña”, en España Popular, núm. 267, 16 de noviembre de 1945.

- "La Asamblea de hermandades de labradores y ganaderos", en España Popular, núm. 321, 22 de noviembre de 1946.

- “La crisis de la industria en Guipúzcoa”, en España Popular, núm. 392, 2 de abril de 1948.

- "La crisis de la industria y del comercio", en España Popular, núm. 403, 18 de junio de 1948. 
- "Los capitalistas españoles se pronuncian contra el sistema franquista y por la libertad de la industria y el comercio", en España Popular, núm. 337, 14 de marzo de 1947.

- Márquez, Antonio, Sobrela situación de España, México, Libro-Méx, 1958.

- Miranda, J osé Antonio y J uan Francisco Pérez Ortiz, "Poder político y favor económico. El Archivo de Nuevas Industrias como fuente para el análisis de las presiones políticas en una economía intervenida", en I Encuentro de I nvestigadores del Franquismo, Barcelona, noviembre de 1992.

- Molinero, Carme y Pere Y sás, "Los industriales catalanes durante el franquismo", en Revista de Historia Económica, núm. 1, año 1990.

- Moreno, Roque, La autarquía en Alicante (1939-1952), Alacant, Institut de Cultura J uan Gil-Albert, 1995.

- Moya, Carlos, El poder económi co en España (1939-1970), Madrid, Tucar, 1975.

- Muñoz, Arconada, Felipe, España, colonia yanqui, México, Nuestro Tiempo, noviembre de 1951.

- Muñoz, Máximo, Tragedias y derroteros de España, México, 1952.

- Palafox, J ordi, Atraso económico y democracia. La Segunda República y la economía española, 1892-1936, Barcelona, Crítica, 1991.

- Paniagua, Xavier, La sociedad libertaria. Agrarismo e industrialización en el anarquismo español, 1930-1939, Barcelona, Crítica, 1982.

- "Perspectiva de mayores hambres en España", España Popular, núm. 248, 6 de julio de 1946.

- Prados de la Escosura y Leandro y Vera Zamagni (eds.), EI desarrollo eco nómico en la E uropa del Sur: España eltalia en perspectiva histórica, Madrid, Alianza Universidad, 1992.

- "Racionamiento, estraperlo y hambre", en España Popular, núm. 79, 22 de noviembre de 1941.

- Ramírez Gómez, Ramón, Situación económica y social de España, México, 1959.

- Reyes, Salvador, "J uristas, economistas, sociólogos", en AA. VV., EI exilio español en México, 1939-1982, México, Salvat, Fondo de Cultura Económica, 1983, primera edición en 1962.

- Rojas García, Antonio, España (Semblanza E conómica), México, 1958.

- Rubio, J avier, La emigración dela guerra civil de 1936-1939. Historia del éxodo que se produce con el fin de la II República española, vol. III, Madrid, San Martín, 1977.

- Sumpsi, J osé María, "La modernización de la agricultura y el desarrollo económico", en Papeles de Economía Española, núm. 73, 1997. 
- Tamames, Ramón, Estructura económica de España, Madrid, Guadiana, 1969, cuarta edición.

- Tamames, Ramón, Los monopolios en España, Madrid, zYX, 1967.

- Tamames, Ramón, Los pactos secretos de Franco con E stados U nidos. Bases, ayuda económica, recortes de soberanía, Barcelona, editorial Grijalbo, 1981.

- "Terminemos con la intervención de las cosechas", en España Popular, núm. 675, 4 de septiembre de 1953.

- Torres, Manuel de, J uicio dela actual política económica española, Madrid, Aguilar, 1956.

- Tuñón de Lara, Manuel, España bajo la dictadura franquista (1939-1975), tomo x de Historia de España, Barcelona, Labor, 1982.

- Vázquez Humasqué, Adolfo, "El problema agrario español", Trimestre Económico, núm. 27, México, octubre-diciembre de 1940.

- Velarde Fuertes, J uan, "La base ideológica de la realidad económica española", en J osé Luis García Del gado (dir.), España. Economía, Madrid, Espasa-Calpe, 1988.

- Viñas, Ángel, Guerra, dinero, dictadura. Ayuda fascista y autarquía en la España deFranco, Barcelona, Crítica, 1984.

- Viñas, A., Los pactos secretos de Franco con Estados Unidos. Bases, ayuda económica, recortes de soberanía, Barcelona, Editorial Grijalbo, 1981. 